\title{
Comportamento Supersticioso em Esquemas Múltiplos: Estudo sobre a Interação do Comportamento Verbal com o Comportamento Mantido por Relação Acidental com Reforço ${ }^{1}$
}

\author{
Marcelo Benvenuti \\ Paulo Panetta \\ Cássia da Hora \\ Silvia Ferrari \\ Pontifícia Universidade Católica de São Paulo
}

\begin{abstract}
RESUMO
A interação do comportamento "supersticioso" com o comportamento verbal foi avaliada em três experimentos. Os participantes receberam diferentes instruções sugerindo que responder poderia produzir pontos. Nas sessões experimentais, a cor de um retângulo que aparecia no monitor de um computador era relacionada à vigência de uma situação de apresentação de pontos independentemente do responder ou à vigência de outra situação em que os pontos não eram apresentados (mult VT $8 \mathrm{~s}$ EXT). Ao final de cada sessão, os participantes tinham que descrever o que faziam na sessão. Nos três experimentos, apenas alguns participantes desenvolveram comportamento "supersticioso", independentemente do tipo de instrução apresentada no início da sessão. Ao final das sessões, os participantes descreviam seus próprios comportamentos. Os resultados sugerem que o desempenho não-verbal do participante controlou seus auto-relatos e que as próprias contingências do esquema múltiplo foram responsáveis pelo comportamento "supersticioso" mais do que instruções ou autorelatos.
\end{abstract}

Palavras-chave: comportamento "supersticioso"; contigüidade; instruções; comportamento verbal.

\begin{abstract}
Superstitious Behavior in Multiple Schedules: a Study About Interaction Among Verbal Behavior and Behavior Maintained by Accidental Relationship with Reinforcement
\end{abstract}

The interaction between "superstitious" behavior and verbal behavior was evaluated in three experiments. The participants received different instructions suggesting that responses could score points. In experimental sessions, a rectangle's color on the computer screen indicated a situation of point presentarion regardless of the participant's responses or another situation in which the points could not be presented (mult VT $8 \mathrm{~s}$ EXT). At the end of each session, participants had to describe what they were doing. In three experiments, only a few participants developed "superstitious" behavior, regardless of the kind of instruction presented at the beginning of the session. At the end of the sessions, participants described their own behavior. The results indicate that the non-verbal performance of the participants controlled their self-assessment and that the very contingencies of multiple schemes were responsible for the "superstitious" behavior, more than self-assessment or instructions.

Keywords: "superstitious" behavior; contiguity; instructions; verbal behavior.

A relação entre o dizer e o fazer faz parte das preocupações de analistas do comportamento já há algumas décadas (Risley \& Hart, 1968; Shimoff \& Catania, 1998; Catania, 2003). O tema é especialmente importante se considerarmos o papel do comportamento verbal para o autoconhecimento, tema central no Behaviorismo Radical (ver, por exemplo, Skinner, 1974). Um aspecto pouco explorado experimental- mente na análise do comportamento, contudo, é a relação entre dizer e fazer quando da construção de causalidade envolvendo eventos do mundo ou envolvendo o próprio responder e eventos do mundo.

A compreensão de como as relações de causalidade são construídas, e suas implicações para os aspectos práticos os mais diversos, parece ser um ponto especialmente contrastante entre a orientação Com- 
portamental Cognitiva e a da Análise do Comportamento. A Psicologia Cognitiva Clínica, por exemplo, enfatiza as interpretações que as pessoas têm do mundo para explicar a formação de quadros clínicos, como a depressão. Em quadros depressivos e em certos transtornos, de acordo com a análise de Beck e Freeman (1993), as pessoas passam a responder generalizadamente a partir de regras eficazes apenas para alguns contextos. Como apontam os autores, "este viés de interpretação e o conseqüente comportamento é configurado por crenças disfuncionais" (p. 23).

$\mathrm{Na}$ Análise do Comportamento, a interação de contingência e contigüidade na constituição de relações operantes é o ponto de partida para a compreensão do que pode ser chamado de distorção ou ilusão no modo como as pessoas constroem relações de causalidade envolvendo comportamento e eventos do mundo. A partir dos resultados de um experimento realizado em 1948, Skinner (1948/1972) mostrou como organismos não-verbais, pombos, tiveram seus comportamentos afetados pela apresentação de alimento independentemente de suas respostas. Os pombos passaram a se comportar como se houvesse uma relação causal entre o que faziam e a apresentação do alimento. O experimento demonstrava o efeito da seleção acidental do responder, seleção pela mera contigüidade entre uma ação que o pombo estivesse casualmente realizando e o alimento. Responder mantido por relação acidental com reforço tem sido chamado na Análise do Comportamento de comportamento "supersticioso".

Há muitas diferenças entre o responder mantido por relação acidental com reforço e o mantido por relação de contingência entre resposta e reforço. Sobretudo, essa diferença diz respeito à maior variabilidade no responder e à dificuldade de manutenção do responder ao longo da continuidade da situação que gerou o responder "supersticioso" (ver, por exemplo, Herrnstein, 1966). O efeito de seleção acidental, tem sido, contudo, documentado em uma série de trabalhos experimentais com não-humanos (p. ex. Eldridge, Pear, Torgrud \& Evers, 1988; Pear, 1985) e humanos (p. ex. Ono 1987; Weisberg \& Kennedy, 1969).

A literatura em Análise do Comportamento tem mostrado que o comportamento pode ser afetado por descrições de contingências que não correspondem às dispostas pelo ambiente, descrições formuladas pelos próprios participantes (p. ex. Heltzer \& Vyse, 1994; Rudski, Lischner \& Albert, 1999) ou fornecidas pelo experimentador (Ono, 1994). Conforme discussão empreendida por Heltzer e Vyse (1994), auto-descri- ções podem ser caracterizadas como "regras supersticiosas" quando sugerem que certas respostas produzem mudanças ambientais quando na verdade não produzem. O termo "supersticioso", aplicado a determinado antecedente ou resposta verbal, não deve ser confundido com o termo "comportamento supersticioso" tal qual utilizado por Skinner em 1948. Embora os dois termos sejam usados para fenômenos que podem interagir, o termo "regra supersticiosa" é aplicado para um antecedente verbal ou para uma resposta verbal que descreve uma contingência que não existe no ambiente não-verbal. Comportamento "supersticioso", por sua vez, é um termo aplicado para uma relação comportamental em que o responder é fortalecido havendo, entre resposta e mudança ambiental, apenas contigüidade.

Heltzer e Vyse (1994) trabalharam com uma situação experimental em que seqüências de oito respostas deveriam ser distribuídas em duas chaves. Em condições em que as seqüências eram reforçadas de acordo com um esquema de razão randômica, os participantes do estudo tenderam a dizer que certas seqüências eram corretas e outras não. As descrições dos participantes foram consideradas regras "supersticiosas" porque não importava quais as seqüências realizadas para a produção da conseqüência; a conseqüência era apresentada a depender de uma programação do experimentador, bastando que o participante respondesse nas duas chaves, apresentando metade das respostas em uma chave e metade na outra. $O$ que os autores chamaram de "regras supersticiosas" foram mais freqüentes quando as seqüências eram reforçadas de acordo com o esquema de razão randômica 2 (RR 2) do que quando reforçadas de acordo com o esquema de razão fixa 1 ou 2 (FR 1 ou FR 2).

Descrições que sugerem relações causais entre respostas e mudanças ambientais e o comportamento "supersticioso" podem interagir. Ninnes e Ninnes (1998; 1999) mostraram que auto-descrições "supersticiosas" podem contribuir para a manutenção do padrão "supersticioso". No artigo de 1998 os autores mostram que o responder "supersticioso" requer a exposição a descrições de contingências que sugerem que o participante deve responder em conjunto com a apresentação de eventos ambientais que independem da resposta. Higgins, Morris e Johnson (1989) já haviam examinado a interação entre instruções e comportamento "supersticioso" em um experimento realizado com crianças. Esses pesquisadores apresentavam às crianças a descrição de uma contingência que não correspondia à contingência disposta ao longo 
do experimento: os pesquisadores diziam que as crianças poderiam ganhar bolinhas de gude caso pressionassem o nariz de um boneco na forma de palhaço. Os participantes passaram por cerca de 15 sessões nas quais as bolinhas eram apresentadas de acordo com um esquema múltiplo de tempo variável e extinção (mult VT EXT): períodos sinalizados de apresentação das bolinhas independente de respostas eram intercalados a períodos sinalizados de ausência de apresentação das bolinhas. As crianças começaram as sessões respondendo nos dois períodos do esquema múltiplo. Ao final das sessões, respondiam apenas no componente VT. Os resultados desse trabalho não podem ser atribuídos apenas ao efeito da apresentação da instrução, uma vez que os pesquisadores observaram responder diferencial no esquema múltiplo: as crianças respondiam no componente VT e deixavam de fazê-lo no componente EXT. O responder "supersticioso" deve ser entendido necessariamente como um produto da instrução combinado a reforço acidental do responder.

Os resultados de Higgins e cols. (1989) sugerem que instruções indicando que respostas são efetivas na produção de mudanças ambientais, fornecidas por um outro (experimentador), podem facilitar o comportamento "supersticioso". Ono (1994) sugeriu que o controle da regra "supersticiosa" poderia depender da fonte que fornece uma descrição de contingências, de maneira que auto-regras poderiam ter um poder maior em induzir comportamento "supersticioso". Essa discussão tem um ponto de interface importante com a apontada acima sobre a construção de relações de causalidade. Expostos a determinadas tarefas, participantes podem descrever relações de contingência entre ações e ambiente mesmo que a contingência não exista. Uma questão ainda em aberto é sobre o papel dessas descrições: como tais descrições atuam como antecedentes para outros comportamentos? Como tais descrições surgem e se mantém no repertório verbal de uma pessoa?

Uma possibilidade é que auto-descrições "supersticiosas" controlem respostas que, uma vez emitidas, passam a ser mantidas por relação acidental com reforço. A avaliação dessa possibilidade depende da investigação da extensão da descoberta de Higgins e cols. (1989), da investigação do quanto as instruções que sugerem relações de dependência entre respostas e mudanças ambientais podem vir a facilitar o surgimento de comportamentos "supersticiosos".

Outra análise possível é que descrições "supersticiosas" sejam apenas auto-relatos sob controle do próprio comportamento. Ao invés de induzirem o comportamento "supersticioso", regras "supersticiosas" podem ser efeitos das mesmas contingências que geraram o responder mantido por relação acidental com reforço. Evidência a favor dessa interpretação tem sido produzida por trabalhos experimentais mais recentes em que o comportamento "supersticioso" é avaliado pelo grau de controle que uma pessoa julga ter sobre determinada tarefa em que o ambiente muda a despeito de seu próprio comportamento (p. ex., Aeschleman, Rosen, Williams, 2003; Bloom, Vernard, Harden \& Seetharaman, 2007).

Parece ser especialmente importante investigar como interagem instruções que induzem o responder fornecidas pelo outro ou criadas pelo próprio participante -, e comportamento "supersticioso". Procedimentos que tornem possível a comparação direta do responder verbal com o não-verbal podem ajudar nessa investigação. A avaliação simultânea de comportamento "supersticioso" e do efeito de regras "supersticiosas" permite avaliar a possibilidade que o verbal controle o não-verbal ou o não-verbal controle o verbal quando descrições de contingências não correspondem às dispostas pelo ambiente.

No presente trabalho, são relatados três experimentos em que se testou a possibilidade de comportamento "supersticioso" ser facilitado por uma descrição que sugeria uma contingência que não existia entre resposta e mudanças ambientais. Os três experimentos são replicações do trabalho de Higgins e cols. (1989) com alterações no tipo de instrução e na história experimental dos participantes. O objetivo principal foi avaliar até que ponto o desempenho observado no estudo de Higgins e cols. (1989) dependeu das instruções fornecidas pelo experimentador, das descrições feitas pelos próprios participantes ou das contingências programadas para a tarefa experimental independentemente de descrições de contingências apresentadas no início das sessões.

\section{MÉTODO GERAL}

\section{Participantes}

Os experimentos contaram com a participação de estudantes universitários, alunos da PUC-SP, USP e Faculdade São Bento. Os participantes foram recrutados por convite feito por um dos experimentadores em sala de aula da universidade em que estudavam. Todos os participantes assinaram Termo de Consentimento Livre e Esclarecido aprovado pela comissão de Ética em Pesquisa da PUC-SP. 


\section{Local e equipamento}

As sessões experimentais foram conduzidas em uma sala de $3,5 \mathrm{~m} \times 2,5 \mathrm{~m}$ de largura localizada no Laboratório de Psicologia Experimental da PUC-SP. $\mathrm{Na}$ sala havia um computador Pentium 1 em cima de uma mesa. Os participantes, sentados em uma cadeira na frente do monitor do computador, manipularam um mouse. Para a condução das sessões, foi utilizado o programa PROG REF V3 (Costa \& Banaco, 2002).

\section{Procedimento}

A tarefa experimental consistia em uma atividade cujo objetivo era acumular pontos. Os participantes podiam responder com o mouse em um retângulo que aparecia na tela do computador com cores alternadas (verde e amarelo). Os participantes entravam na sala de coleta depois que o experimentador já havia programado as contingências experimentais. Com o participante sentado, o experimentador lia a seguinte instrução, denominada de Instrução Geral (utilizada nos Experimentos 1 e 2):

Esta atividade da qual você está participando não tem o intuito de medir o nível da sua inteligência ou traçar definições da sua personalidade. É apenas uma atividade que visa investigar as possiveis relações entre uma tarefa realizada no computador e as possiveis hipóteses que você formulará enquanto estiver realizando-a. Durante a tarefa você poderá utilizar o mouse para clicar em um retângulo que aparecerá na tela.

No Experimento 3, a Instrução Geral mudou para:

\begin{abstract}
Obrigada por sua participação nesta pesquisa. A atividade da qual você participa não tem o intuito de medir a sua inteligência ou traçar definições da sua personalidade. E apenas uma atividade que visa investigar as possiveis relações entre uma tarefa realizada no computador e as hipóteses que você formulará enquanto estiver realizando-a. Durante a tarefa você poderá utilizar o mouse para clicar em um retângulo que aparecerá na tela. Você deverá participar de cerca de cinco sessões experimentais com duração de mais ou menos cinco minutos cada. Você poderá desistir de sua participação a qualquer momento.
\end{abstract}

Depois da Instrução Geral, o experimentador pedia ao participante que começasse a atividade. Na tela já havia uma mensagem dizendo que para iniciar a sessão experimental o participante deveria responder em um retângulo em que estava escrito "OK". Ao responder na mensagem, aparecia uma instrução escrita na tela informando que o participante poderia/deveria responder com o mouse sobre os retângulos que apareceriam na tela do computador para acumular pontos. Ao terminar de ler, o participante clicava em "OK" e iniciava de fato a sessão.

Em cada sessão experimental, o esquema de reforçamento utilizado foi o múltiplo com componentes de tempo variável e extinção (mult VT EXT). Cada um dos componentes era sinalizado a partir da mudança de cor de um retângulo exibido na tela do computador. Nesse retângulo, o participante pôde emitir respostas com o mouse. Durante a vigência do componente VT, o retângulo era verde e os pontos eram apresentados em média a cada oito segundos, independente das respostas do participante (VT $8 \mathrm{~s}$ ). Os intervalos do esquema VT 8 s foram: $2 \mathrm{~s}, 5 \mathrm{~s}, 8 \mathrm{~s}, 10 \mathrm{~s}$ e $15 \mathrm{~s}$, sorteados randomicamente pelo programa. Durante o componente EXT, o retângulo era amarelo e os pontos não eram apresentados.

Cada sessão teve a duração de 5 minutos, com cinco apresentações de cada componente. Cada componente ficava em vigor 30 segundos por apresentação, independente das respostas do participante no retângulo. Os componentes eram alternados randomicamente durante a sessão, podendo haver mais de uma apresentação de um mesmo componente em seguida. Não foi permitido que o mesmo componente fosse repetido mais do que três vezes consecutivas.

\section{Instruções mínimas e incorretas}

Cada sessão experimental começava com a apresentação de uma instrução. Ao longo dos três experimentos, relatados em detalhes a seguir, foram utilizadas as instruções apresentadas abaixo. No texto, a parte em itálico (que não existia quando a instrução aparecia no computador) destaca o que se dizia que o participante deveria fazer.

Instrução Mínima (MIN): "Nesta etapa, você acumulará pontos que serão apresentados no canto superior do monitor do computador. Você pode clicar com o mouse em um retângulo que ora aparecerá com uma cor e ora com outra. Quando finalizarmos esta etapa, aparecerá um aviso na tela."

Instrução Incoerente 1 (INC 1): "Nesta etapa, você acumulará pontos que serão apresentados no canto superior do monitor do computador. Para ganhar os pontos você deve clicar com o mouse em um retângulo que ora aparecerá com uma cor e ora com outra. 
Quando finalizarmos essa etapa, aparecerá um aviso na tela".

Instrução Incoerente 2 (INC 2): "Você irá participar de algumas sessões experimentais. Durante cada uma delas, você irá acumular pontos que serão apresentados no canto superior do monitor do computador. Para ganhar os pontos, você deve clicar com o mouse em um retângulo que aparecerá na tela durante cada uma das sessões. Este retângulo ora aparecerá com uma cor ora com outra. Quando o retângulo estiver de uma determinada cor você poderá ganhar os pontos, quando o retângulo estiver com outra cor você não poderá ganhar os pontos mesmo que clique sobre ele. Tente ganhar o maior número de pontos possível!"

A diferença fundamental entre as instruções foi em relação ao que era dito aos participantes sobre o que deveriam fazer na sessão para ganhar os pontos. $\mathrm{Na}$ Instrução MIN, procurou-se oferecer o mínimo de informação sobre a relação resposta/apresentação de pontos. Na Instrução INC 1, era descrito uma relação incorreta entre resposta e mudança ambiental, sem a especificação de em qual componente o participante deveria responder. Na Instrução INC 2, a descrição falaciosa da contingência era mais explícita, pois indicava que o participante deveria responder em apenas um dos componentes do esquema múltiplo para produzir os pontos.

Alguns participantes receberam alguma das instruções de modo diferente ou a própria instrução sofreu alteração em alguns momentos do estudo. Essas exceções serão apresentadas oportunamente, ao longo da descrição dos experimentos.

\section{Coleta de relatos verbais}

Relatos verbais foram coletados de diferentes modos, especificados em detalhes na seção de procedimento de cada um dos três experimentos relatados a seguir. Relatos pós-sessão foram coletados a partir de perguntas feitas por escrito, às quais o participante respondia também por escrito. Para dois participantes do Experimento 1 e para os participantes do Experimento 3 foi introduzida uma pergunta antes da sessão para avaliar que controle verbal a instrução produzia no participante (entre outras coisas, para avaliar se o participante havia compreendido a instrução). A estratégia para essa avaliação foi perguntar por um palpite do participante a respeito do que ele deveria fazer na tarefa. Essa avaliação foi criada por conta da observação freqüente de desempenhos que não tinham relação com a instrução oferecida antes da sessão.

\section{EXPERIMENTO 1}

O objetivo do Experimento 1 foi avaliar o efeito de uma instrução que sugeria uma relação de contingência entre resposta e apresentação de pontos sobre o desempenho em mult VT EXT. Para tanto, os participantes receberam, no início das sessões, ou uma instrução, mínima, genérica, ou uma instrução que sugeria dependência entre resposta e apresentação de pontos.

\section{Método do Experimento 1}

Participantes: Seis estudantes do curso de psicologia da PUC-SP participaram do estudo.

Procedimento: Depois de apresentada a instrução geral, a continuação do experimento dependeu do participante ter sido aleatoriamente designado para uma das duas condições pré-definidas como Instrução Mínima ou Instrução Incoerente.

Para os participantes P1 e P2 a instrução apresentada em seguida à Instrução Geral diferiram das descritas na seção de Método Geral. As instruções apresentadas para esses dois participantes foram as descritas a seguir:

Instrução Mínima (MINa): "Nesta etapa, você irá acumular pontos que serão apresentados no canto superior do computador. Você poderá clicar com o mouse em um retângulo que ora aparecerá com uma cor e ora aparecerá com outra. Quando finalizarmos a atividade aparecerá um aviso na tela. Como este é um experimento sobre hipóteses, queremos que você dê um palpite antes de começar a trabalhar na atividade. Arrisque uma hipótese sobre o que deve ser feito. Qual o seu palpite?".

Instrução Incoerente (INCa): "Nesta etapa, você irá acumular pontos que serão apresentados no canto superior do computador. Para ganhar pontos, você deverá clicar com o mouse em um retângulo que ora aparecerá com uma cor e ora aparecerá com outra. Quando finalizarmos a atividade aparecerá um aviso na tela. Como este é um experimento sobre hipóteses, queremos que você dê um palpite antes de começar a trabalhar na atividade. Arrisque uma hipótese sobre o que deve ser feito. Qual o seu palpite?".

P1 e P2 participaram cada um de três sessões experimentais. P1 recebeu apenas a Instrução MINa e P2 apenas a Instrução INCa.

No início de cada sessão, depois de lida a Instrução Geral acerca do objetivo da atividade e depois de ler no monitor a instrução correspondente à condição 
experimental na qual seria submetido, o participante recebia um papel com a pergunta: "Qual o seu palpite?" Depois de responder por escrito, iniciava-se a tarefa. Ao final de cada sessão, o participante deveria responder também por escrito à seguinte solicitação: "Formule uma hipótese sobre o que você deveria ter feito na tarefa". O objetivo do relato ao final da sessão foi possibilitar a comparação do comportamento verbal do participante com seu desempenho não-verbal. $\mathrm{O}$ objetivo dos palpites, em especial, era avaliar o controle que a instrução gerava sobre o comportamento verbal dos participantes (entre outras coisas, se o participante havia entendido a instrução).

A partir dos resultados de P1 e P2 e de uma análise do procedimento, as instruções foram modificadas para as descritas na seção de Método Geral, pois a diferença entre a Instrução INCa e MIN não era evidente. Além disso, extinguiu-se a solicitação do relato verbal inicial do participante, o palpite, pois os participantes falavam de hipóteses mais gerais sobre a atividade, não do que faziam ou fariam nos retângulos verde e amarelo. A solicitação do relato verbal ao final de cada sessão foi preservada, pois continuou fazendo parte do objetivo do estudo comparar o comportamento verbal dos participantes com os seus desempenhos não verbais. Além disso, seria possível avaliar se os participantes formulariam uma nova descrição igual ou não à instrução fornecida no início da sessão.

Depois das modificações, o experimento contou com mais quatro participantes. As instruções oferecidas a eles, depois de lida a Instrução Geral foram as descritas na seção de Método Geral, Instrução MIN ou Instrução INC $1^{2}$.

A Tabela 1 mostra o número de sessões a que os participantes foram submetidos e o tipo de instrução que era apresentada na tela do computador no início de cada sessão.

\section{TABELA 1}

Participantes, número de sessões e tipo de instrução apresentada no início da sessão, Instrução Mínima (MIN), Instrução Mínima (MIN1), Instrução Incoerente (INCa) ou Instrução Incoerente 1 (INC 1).

\begin{tabular}{ccccccc}
\hline Sessões & \multicolumn{5}{c}{ Participantes } \\
\cline { 2 - 6 } & P1 & P2 & P3 & P4 & P5 & P6 \\
1 & MINa & INCa & MIN & MIN & INC 1 & INC 1 \\
2 & MINa & INCa & MIN & MIN & INC 1 & INC 1 \\
3 & MINa & INCa & MIN & MIN & INC 1 & INC 1 \\
4 & & & INC 1 & MIN & INC 1 & \\
5 & & & INC 1 & MIN & INC 1 & \\
6 & & & MIN & & \\
\hline
\end{tabular}

Antes de iniciar a coleta, os participantes já haviam sido aleatoriamente designados para receber a Instrução MIN ou a INC 1 De início, cada participante iria ser exposto a três sessões com apenas um tipo de instrução. Esse critério, contudo, não foi mantido e alguns dos participantes foram expostos a mais sessões da mesma condição inicial ou a mais sessões com a Instrução INC 1. A extensão no número de sessões serviu para testar o efeito da continuidade de exposição às mesmas contingências ou para avaliar, no caso de P3, o efeito da introdução da instrução INC 1 depois da história com a instrução MIN.

\section{Resultados e Discussão do Experimento 1}

$\mathrm{Na}$ situação de esquema múltiplo, responder sistemático no componente de apresentação de pontos independente do responder (VT) e não em extinção (EXT) indica que o responder está sendo mantido pela relação das respostas com apresentação dos pontos independentes do responder. Responder tanto em VT quanto em EXT indica que o responder está sob controle das instruções. Baixo número de respostas nos dois componentes indica que o responder está sob controle das contingências programadas (em ambos os componentes as respostas não alteram a probabilidade da apresentação dos pontos. Em extinção, não acontece apresentação de pontos; em VT, os pontos são apresentados independentemente das respostas do participante). 
A Figura 1 mostra o número de respostas dos participantes nos componentes VT e EXT ao longo das sessões realizadas. P1 e P4 receberam apenas a Instrução MIN (ou MINa). P3 recebeu as instruções MIN e INC 1. Na Figura 1, a linha pontilhada separa os dados antes e depois da introdução da Instrução INC 1. P2, P5 e P6 receberam apenas a Instrução INC 1 (ou INCa).

Dos participantes que receberam a Instrução MIN, apenas P1 emitiu mais respostas em VT do que em EXT. P1 mantém um número constante de respostas em EXT, emitindo por volta de 150 a 200 respostas em cada sessão. No componente VT, P1 começou emitindo 295 e apresentou mais respostas a cada sessão. Na terceira, emitiu 762 respostas em VT. P4 e P5 apresentam número de respostas similar nos componentes ao longo das sessões. P4 mantém uma média próxima de 400 respostas em cada componente e P5 uma média de 50 respostas. P3 vinha respondendo indiferenciadamente em VT e em EXT nas três sessões com a Instrução MIN. Na primeira sessão com a Instrução INC, o número de respostas em VT foi maior do que em EXT (97 respostas em VT e 22 em EXT). $\mathrm{Na}$ segunda sessão, há perto de 30 respostas tanto em VT quanto em EXT.

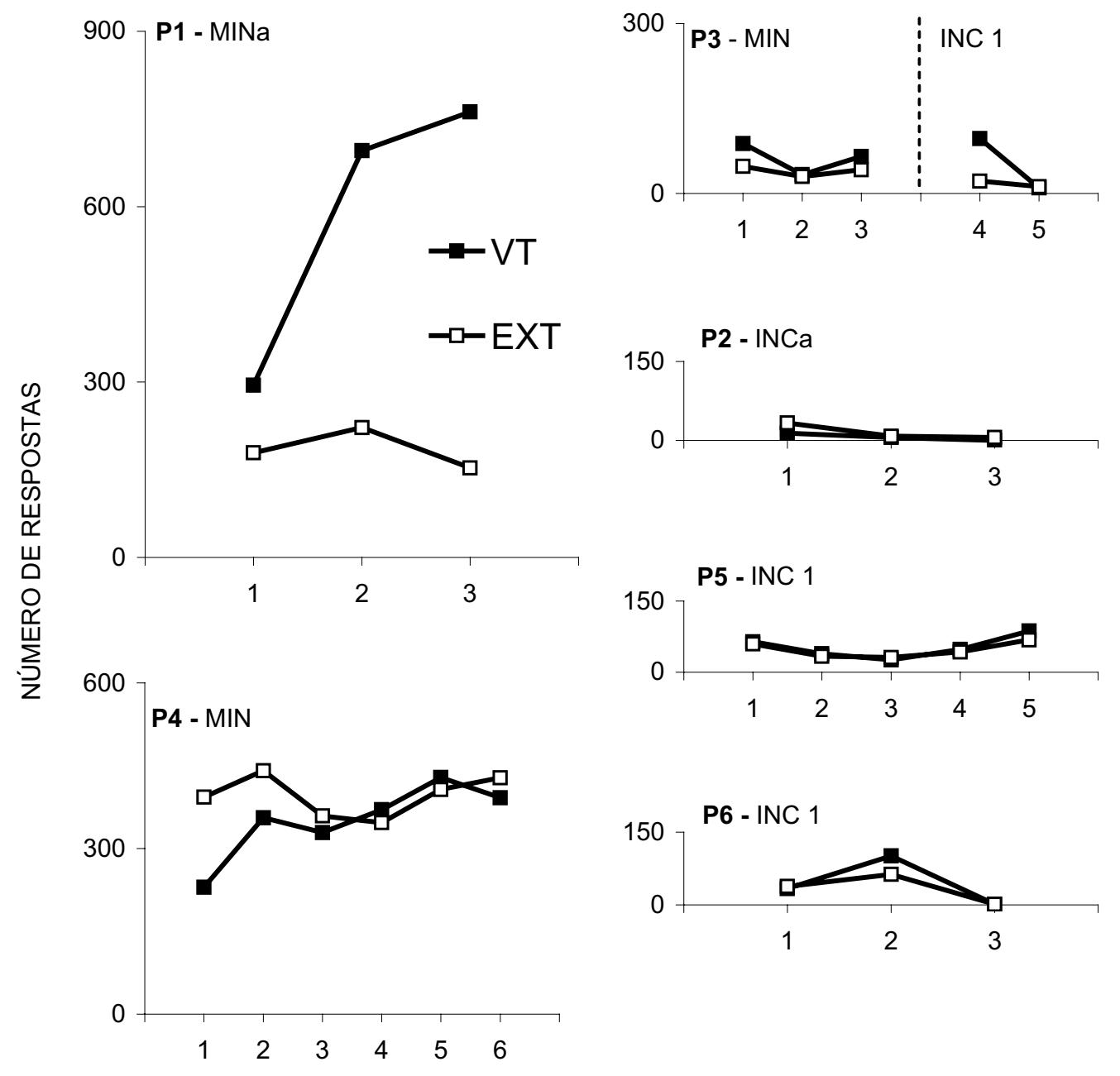

SESSÕES

Figura 1. Número de respostas nos componentes do esquema múltiplo ao longo das sessões do Experimento 1. P1, P4 e P5 receberam apenas a Instrução MIN (ou MINa). P3 recebeu a Instrução MIN nas três primeiras sessões e a Instrução INC nas duas últimas (a linha pontilhada no gráfico desse participante indica a mudança de instrução no início da sessão. P2, P5 e P6 receberam a Instrução INCa ou INC 1. 
O padrão de responder consistente em VT acompanhado de redução no número de respostas em EXT, indicativo do comportamento "supersticioso", só foi observado em um dos seis participante do Experimento 1 (na terceira sessão com o mult VT EXT, P1 emitiu 152 respostas em EXT e 762 respostas em VT). P1 recebeu apenas a Instrução MINa. Para P3, há um pequeno efeito da introdução da Instrução INC 1. Para os demais participantes, não há qualquer indício de que a apresentação de pontos em VT tenha facilitado o responder "supersticioso".

A apresentação da Instrução MIN foi feita para aumentar as chances de exposição direta às contingências programadas para casa sessão, a fim de, a partir da comparação com os resultados obtidos com a apresentação da Instrução INC 1, avaliar o papel da instrução falaciosa para a produção do comportamento "supersticioso". Os resultados não mostram o efeito diferencial da Instrução INC 1. Isso pode ter acontecido por conta do tipo de tarefa utilizada, em que foi medido o número de respostas. Nesse caso, parece que qualquer instrução que faça referência a uma resposta de algum modo exerce controle sobre ela. Ou seja, em uma atividade em que o fenômeno comportamental seja avaliado pela emissão de respostas (seja medida pela taxa ou pela freqüência), é indiferente se a instrução é mínima ou incoerente, pois a menção à resposta já produz algum tipo de controle. Possivelmente, o efeito de instruções mínimas e incoerentes faz diferença quando as atividades envolvem responder com determinados padrões em diferentes esquemas de reforço (ver, por ex., Assis, 1995).

Uma possível interpretação para os resultados obtidos com o Experimento 1 é que o responder em EXT tenha sido reforçado e mantido pela relação temporal da resposta na extinção com a mudança de componente. $\mathrm{O}$ responder no componente EXT pode ter sido reforçado pela apresentação do estímulo - cor verde relacionado ao componente VT.

Relatos Verbais: Os participantes responderam de formas diferentes às perguntas feitas ao longo do experimento. Para quatro dos seis participantes, pelo menos uma das respostas descrevia uma contingência que não estava de fato em vigor. P1 começou respondendo "ainda não descobri" (P1, Sessão 1), e, ao final: "Quanto mais rápido eu clicava no botão verde, mais eu ganhava pontos. No amarelo, não sei" (P1, Sessão 3). P2 apresentou um relato "supersticioso" apenas na primeira sessão, respondendo: "Só adianta clicar no verde, pois o amarelo não deu pontos" (P2, Sessão 1).
Na última sessão, P2 escreveu: "Não era preciso fazer nada, pois o retângulo verde apresenta os pontos aleatoriamente e o amarelo estava em extinção" (P2, Sessão 3). Alguns relatos são interessantes porque sugerem outras seqüências causais "supersticiosas" que não envolviam apenas clicar no retângulo verde. "Não sei se era bem isso, mas acho que deveria contar, por exemplo: depois de quantos cliques eu ganhava pontos ou em que seqüência que eu deveria clicar" (P4, Sessão 1). Ou: "O amarelo precisa clicar cinco vezes e esperar um pouco. $\mathrm{O}$ verde continua parecendo que muda conforme o tempo" (P5, Sessão 5). Tal qual observado no desempenho não-verbal, houve também bastante variabilidade no desempenho verbal: variabilidade tanto entre os participantes como ao longo das sessões de um mesmo participante.

\section{EXPERIMENTO 2}

Os resultados do Experimento 1 chamam a atenção por serem bastante diferentes dos relatados por Higgins e cols (1989). Por esse motivo, o Experimento 2 variou algumas características do procedimento empregado no Experimento 1. Com o objetivo de eliminar a relação temporal do responder no componente EXT com a apresentação do componente VT, o procedimento do Experimento 1 foi replicado com a introdução de um intervalo para a mudança de componentes do esquema múltiplo. Durante um intervalo de $5 \mathrm{~s}$, a contingência programada era suspensa entre a apresentação de um componente e o seguinte. Essa variação justificou-se pela análise feita a partir dos resultados encontrados no Experimento 1, em que supunha-se que a mudança da cor do retângulo, não os pontos, tenham fortalecido acidentalmente o responder. Além da Instrução INC 1, utilizada no Experimento 1 , foi criada a Instrução INC 2, na qual a descrição falaciosa da contingência era mais explícita, pois indicava que o participante deveria responder em apenas um dos componentes do esquema múltiplo para receber os pontos. O objetivo da mudança no tipo da instrução foi investigar se uma instrução mais explícita facilitaria o desenvolvimento do comportamento "supersticioso".

\section{Método de Experimento 2}

Participantes: Cinco estudantes universitários, alunos dos cursos de Ciências Sociais e Direito da PUCSP, de História da USP ou de Filosofia da Faculdade São Bento participaram do estudo. 
Procedimento: Durante a mudança de componente do esquema múltiplo, a tela do computador ficava escura e exibia uma mensagem solicitando que o participante aguardasse um momento. O período de intervalo para mudança tinha a duração de 5 segundos. Só havia esse intervalo quando o novo componente apresentado era diferente do anterior.
Quando não era apresentada a nova Instrução Incoerente (Instrução INC 2), a antiga Instrução Incoerente (INC 1, do Experimento 1) aparecia no início da sessão. A Tabela 2 mostra o tipo de instrução apresentada no início de cada sessão para os participantes do Experimento 2. No Experimento 2, diferente do que acontecia no Experimento 1, os participantes não receberam a Instrução MIN.

TABELA 2

Participantes, Número de Sessões e Tipo de Instrução Apresentada no Início da Sessão, Instrução Incoerente (INC 1, como no Experimento 1) ou a Instrução Incoerente 2, em que era Enfatizado que o Participante só Deveria Responder em um dos Retângulos (INC 2)

\begin{tabular}{cccccc}
\hline Sessões & \multicolumn{5}{c}{ Participantes } \\
\cline { 2 - 6 } & P7 & P8 & P9 & P10 & P11 \\
\hline $\mathbf{1}$ & INC 2 & INC 1 & INC 1 & INC 1 & INC 1 \\
2 & INC 2 & INC 1 & INC 1 & INC 1 & INC 1 \\
3 & INC 2 & INC 1 & INC 1 & INC 1 & INC 1 \\
$\mathbf{4}$ & INC 2 & INC 1 & INC 1 & INC 2 & INC 2 \\
5 & INC 2 & INC 1 & INC 1 & INC 2 & INC 2 \\
$\mathbf{6}$ & & INC 2 & & & INC 2 \\
\hline
\end{tabular}

Como pode ser visto na Tabela 2, o único participante a receber a Instrução INC 2 desde o início foi P7. Os demais receberam antes a Instrução INC $1 \mathrm{e}$, depois, em outras sessões, a Instrução INC 2. Para P8, P9, P10 e P11, as sessões começaram com a instrução utilizada no Experimento 1 para que fosse possível avaliar os efeitos da introdução do intervalo de $10 \mathrm{~s}$ entre as apresentações dos componentes. O critério para a introdução da Instrução INC 2 foi o desempenho não diferenciado em VT e EXT ao longo de três sessões. Quando isso acontecia, a Instrução INC 2 era introduzida; do contrário, a Instrução INC 1 continuava a ser apresentada.

Relatos verbais foram coletados como no Experimento 1 .

\section{Resultados e Discussão do Experimento 2}

No Experimento 2, responder freqüente em VT e não responder em EXT sugere a manutenção do comportamento por relação acidental com a apresentação de pontos. Responder tanto em VT quanto em EXT indica controle pelas instruções ou controle por outras variáveis não controladas. Baixo número de respostas tanto em VT quanto em EXT indica que o responder está sob controle das contingências programadas.

A Figura 2 mostra o número de respostas dos participantes do Experimento 2 nos componentes VT e EXT ao longo das sessões. A linha pontilhada mostra a mudança do tipo de instrução oferecida no início da sessão: dados à esquerda da linha pontilhada são das sessões em que era apresentada a Instrução INC 1; dados à direita da linha pontilhada, de quando era apresentada a Instrução INC 2. Para P7, foi apresentada apenas a Instrução INC 2; para P9, apenas a Instrução INC 1 .

Entre os participantes que apresentaram responder consistente em VT (não respondendo em EXT) em pelo menos uma sessão, destaca-se o desempenho de P9. Os demais participantes apresentam o padrão indicativo do responder "supersticioso", responder em VT e não em EXT, em pelo menos uma sessão (uma exceção possível é o desempenho de P11, cuja análise é dificultada por conta do baixo número de respostas, cerca de 40 em cada componente). 

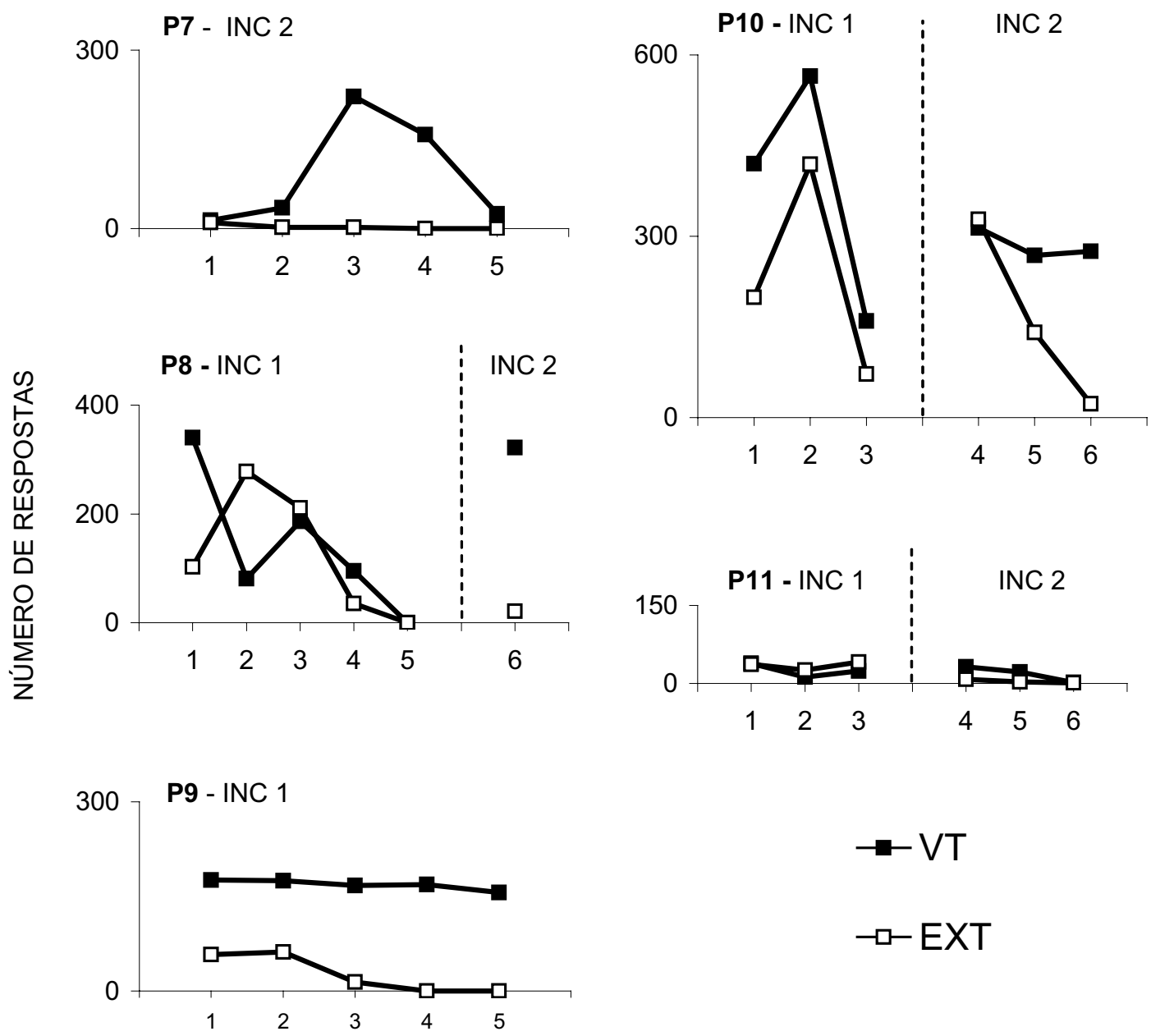

SESSÕES

Figura 2. Número de respostas nos componentes do esquema múltiplo ao longo das sessões do Experimento 2. P7 recebeu apenas a Instrução INC 2; P9, apenas a Instrução INC 1. P8, P10 e P11 receberam a Instrução INC 1 e, nas sessões que aparecem à direita da linha pontilhada, a Instrução INC 2.

Comparando os resultados do Experimento 2 com os do Experimento 1 é possível levantar alguns pontos para discussão: parece ter havido pouca diferença nos resultados em função do tipo de instrução oferecida no início dos experimentos. Os resultados do Experimento 2, em que foi favorecido o comportamento "supersticioso", parecem ter dependido mais das contingências não-verbais do que das instruções, tenham estas enfatizado ou não que o participante deveria responder a apenas um dos componentes. Nesse sentido, a contingência adicional de intervalo para mudança parece ter sido a principal variável facilitadora da diferenciação no responder em VT e EXT.

\section{Relatos Verbais}

Quatro dos cinco participantes apresentaram relatos que sugeriam alguma relação entre responder e mudanças ambientais. P7 sugeriu que havia relação entre responder no retângulo do VT e pontos do início ao fim das sessões. Na primeira sessão, respondeu: "O botão verde aumentava os pontos, o botão amarelo não dava ponto nenhum. Tenho a impressão que quanto mais clicava no botão verde, mais ponto conseguia, ao passo que, quando aparecia o botão amarelo, se clicasse muito nele, ele demorava mais para ir embora. Acho que não deveria clicar no amarelo para ele ir embora logo e voltar a ganhar pontos" (P7, Ses- 
são 1). Na Sessão 5, P7 respondeu: "Deveria ter clicado no botão verde, que acumula pontos. Isso porque o botão amarelo não dá pontos e o objetivo do jogo é obter o maior número possível de pontos" (P7, Sessão 5). Portanto, relatos "supersticiosos" foram mais freqüentes no Experimento 2 do que no Experimento 1.

\section{EXPERIMENTO 3}

O objetivo do Experimento 3 foi avaliar com mais precisão o efeito da Instrução Incoerente criada no Experimento 2 (Instrução INC 2). Novas sessões foram conduzidas com novos participantes sem o intervalo de $10 \mathrm{~s}$ na mudança dos componentes. Como instruções, foram utilizadas as Instruções INC 1 ou INC 2. Palpites foram solicitados a cada sessão, como havia sido feito com os dois primeiros participantes do Experimento 1. Também foi modificado o modo de coletar os relatos pós-sessão, de modo que os resultados do relato fossem comparados ponto a ponto com os resultados na tarefa não-verbal.

\section{Método do Experimento 3}

Participantes: Cinco estudantes de graduação e pós-graduação da PUC-SP participaram do estudo

Procedimento: Depois de lida a Instrução Geral, os participantes recebiam a Instrução INC 1 ou a Instrução INC 2.

Para a coleta dos palpites, a partir da segunda sessão era adicionado à Instrução INC 1 ou 2 o seguinte trecho: "Como este é um experimento sobre hipóteses, você deve dar um palpite antes de começar a atividade. Arrisque uma hipótese sobre o que deve ser feito. Qual o seu palpite? Escreva-o na folha de papel ao seu lado e depois clique no retângulo OK para iniciar a atividade. Obrigado por sua participação".
Da segunda sessão em diante, após escrever o palpite na folha de papel e clicar em "OK", iniciava-se a sessão em que vigorou o esquema mult VT EXT. O intervalo de $10 \mathrm{~s}$ para mudança de componente não esteve em vigor.

Ao final de cada sessão, era entregue ao participante uma folha de papel com as seguintes perguntas: "O que você precisava fazer para ganhar pontos: 1) no botão verde? 2) no botão amarelo?”. Após responder e entregar a folha de papel, uma nova sessão experimental era programada, e assim por diante, até que cinco sessões fossem realizadas.

No início de casa sessão, a Instrução INC 2 era apresentada na tela do computador caso o participante apresentasse um dos seguintes padrões de respostas na sessão anterior: a) diferenciação do responder, havendo mais respostas em EXT do que em VT; b) responder indiferenciado em EXT e VT; c) ausência de respostas em EXT e em VT. A Instrução INC 2 também era apresentada caso o participante completasse três sessões com a Instrução INC 1. "Diferenciação" de responder foi definido como responder cerca de duas vezes mais em um componente do que no outro. "Responder indiferenciado", por sua vez, como no Experimento 2, foi identificado quando o participante apresentava números próximos de respostas nos componentes VT e EXT.

Após receber a Instrução INC 2, o participante deveria concluir mais três sessões experimentais, independente do número de sessões realizadas com a Instrução INC 1.

A Tabela 3 resume as condições do Experimento 3, indicando que instrução cada participante recebia em cada sessão.

TABELA 3

Participantes, Número de Sessões e Tipo de Instrução Apresentada no Início da Sessão, Instrução Incoerente 1 (INC 1), ou Instrução Incoerente 2 (INC 2).

\begin{tabular}{cccccc}
\hline Sessões & \multicolumn{5}{c}{ Participantes } \\
\cline { 2 - 6 } & P12 & P13 & P14 & P15 & P16 \\
\hline 1 & INC 1 & INC 1 & INC 1 & INC 1 & INC 1 \\
2 & INC 2 & INC 1 & INC 2 & INC 2 & INC 2 \\
3 & INC 2 & INC 1 & INC 2 & INC 2 & INC 2 \\
4 & INC 2 & INC 2 & INC 2 & INC 2 & INC 2 \\
5 & INC 2 & INC 2 & INC 2 & INC 2 & INC 2 \\
\hline
\end{tabular}




\section{Resultados}

Como no Experimento 2, responder freqüente em VT e não responder em EXT sugere a manutenção do comportamento por relação acidental com a apresentação de pontos. Responder tanto em VT quanto em EXT indica controle pelas instruções ou controle por outras variáveis não controladas. Baixo número de respostas tanto em VT quanto em EXT indica que o responder está sob controle das contingências programadas.

A Figura 3 mostra, como as figuras anteriores, o número de respostas dos participantes do Experimento 3 nos componentes VT e EXT ao longo das sessões. A Figura 3 mostra também o tipo de relato pós-sessão do participante: se o participante havia dito na sessão que precisava ou não responder aos dois retângulos diferentes. Em cada sessão, abaixo das curvas, barras indicam que o participante havia dito que precisava responder. Ausência de barras indica que o participante havia dito que não precisava responder. Barras brancas indicam a resposta positiva à pergunta sobre responder no componente EXT, enquanto barras escuras indicam a resposta positiva à pergunta sobre responder no componente VT. Dados à esquerda da linha pontilhada são com a Instrução INC 1 e à direita com a Instrução INC 2.

P12 e P14 foram os dois participantes que com mais clareza mostram, em algum momento da coleta, responder sistemático em VT e poucas respostas em EXT. P13 também apresenta o mesmo padrão de P12 e P14. Com a Instrução INC 1, P12, P13 e P14 respondem de maneira indiferenciada em VT e em EXT, apresentando número próximo de respostas em ambos os componentes (como pode ser visto na Figura 3, P12 apresentou cerca de 150 respostas em cada um dos componentes; P13, cerca de 20 respostas em cada componente ao longo de três sessões; e P14 cerca de 400 respostas).

A comparação ponto a ponto do desempenho verbal com o não-verbal possibilita visualizar algumas relações interessantes: por exemplo, que os relatos "supersticiosos" - quando o participante dizia que tinha que responder em VT - ocorrem quando o participante responde em VT. Nas sessões em que não há respostas em VT, não aparecem barras indicando que o participante dizia precisar responder neste componente para produzir pontos. Eventualmente, há relatos de responder apenas em VT mesmo quando há respostas tanto em VT quanto em EXT. É o caso do desempenho de P12 na primeira sessão.

Respostas a "palpites" foram variadas e nem sempre envolviam o que os participantes iriam fazer diante dos retângulos coloridos. P13 foi dos poucos que, na Sessão 2, fez menção ao que faria no retângulo, sem especificar o componente: "Acho que o próximo exercício, quanto menos apertar sobre o quadrado, mais pontos irei acumular, podendo variar outras cores com regras diferentes para cada uma delas (P13, Sessão 2). P15, na segunda sessão, escreveu: "A minha opinião é que não é necessário ficar apertando para os retângulos mudarem de cor, do amarelo para o verde (P15, Sessão 2); na última sessão escreveu: "Clicando nos cantos tracejados do retângulo verde irei ganhar pontos" (P15, Sessão 5). P16 nas últimas sessões apresentou os seguintes palpites: "Nada deve ser feito, os pontos são dados pelo programa, não pelos cliques no mouse" (P16, Sessão 4) e "Mantenho a hipótese de que os pontos são dados pelo programa, mas desta vez eu vou clicar nos dois retângulos o máximo de vezes que conseguir" (P16, Sessão 5). Para os outros participantes, respostas ao "palpite" não faziam menção ao responder nos retângulos, como "Concentração" (P14, Sessão 4). 

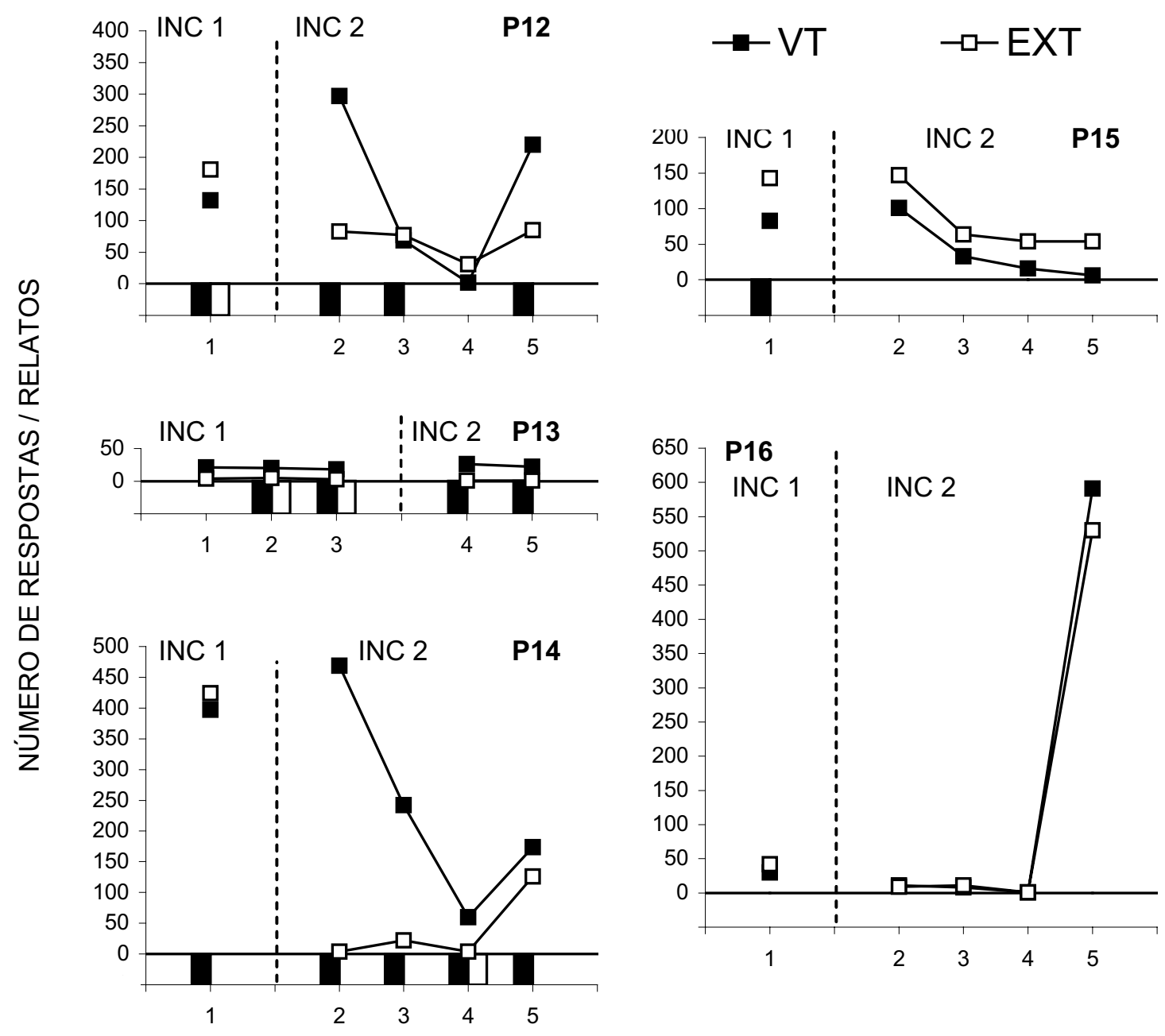

\section{SESSÕES}

Figura 3. Número de respostas nos componentes do esquema múltiplo ao longo das sessões do Experimento 3 e relatos pós-sessão. A presença de barras abaixo das curvas indica a resposta verbal ao questionário pós-sessão (se o participante escreveu que deveria responder ou não para produzir pontos). A ausência de barras, em cada sessão, indica que o participante escreveu que não precisava responder para produzir pontos. Barras brancas representam a resposta para a pergunta sobre o retângulo do componente EXT e barras escuras representam a resposta para a pergunta sobre o retângulo do componente VT.

\section{DISCUSSÃO GERAL}

Os resultados produzidos por este trabalho podem ser, em primeiro, lugar, considerados como uma demonstração adicional de comportamento "supersticioso", contribuindo para a discussão da possibilidade de seleção acidental do comportamento em função de uma relação de contigüidade entre respostas e mudanças ambientais (Skinner, 1948/1972). Os resultados podem ser também considerados uma demonstração adicional de comportamento "supersticioso" em es- quemas complexos (Catania \& Cutts, 1963; Higgins, Morris \& Johnson, 1989).

Higgins e cols (1989) mostraram que um esquema mult VT EXT, um esquema complexo, pode gerar comportamento "supersticioso". O responder diferencial no esquema, responder no VT e não responder em EXT, indica que respostas no VT estão sendo mantidas acidentalmente pela apresentação dos pontos. Nos três experimentos relatados, como no procedimento de Higgins e cols, o responder diferencial no esquema 
múltiplo foi utilizado como forma de avaliar o quanto o comportamento "supersticioso" foi facilitado pela apresentação de instruções que sugeriam que havia relação entre respostas e apresentação de pontos.

Nem todos os participantes do estudo apresentaram comportamentos "supersticiosos", mesmo quando algumas das condições experimentais dos experimentos favoreceram o fortalecimento acidental do responder para um número maior de participantes. Participantes que não apresentaram responder consistente nem em VT nem em EXT ficaram sob controle das contingências programadas - ausência de contingência R-S em EXT pela não apresentação de pontos e ausência de contingência R-S pela apresentação de pontos independente do responder. P2, P5, P6, P11, P13 e possivelmente P16 foram participantes que mostraram desempenho sob controle das contingências programadas. P4, P10, P12 e P14 e P15 tiveram seus desempenhos sob controle das instruções e responderam tanto nos componentes VT como EXT.

Para aqueles que apresentaram comportamento "supersticioso" - P1, P3 (com a Instrução INC 1), P7, P8, P9, P10 (com a Instrução INC 2), P12 e P14 houve variabilidade na manutenção do comportamento: alguns mantiveram-se respondendo em VT ao longo de todas as sessões realizadas (P1 e P9); outros apresentaram responder consistente em VT em poucas sessões (P7, P8, P10, P12 e P14), algumas vezes em apenas uma (P3). Mais do que contestar a pertinência da noção de seleção acidental, essa variabilidade é uma evidência de sua possibilidade. A variabilidade no padrão acidentalmente selecionado mostra como interagem variabilidade no responder e reforço que não depende do responder. Em estudos com seleção acidental do responder, a seleção é de aspectos que fazem parte de uma variabilidade não planejada no experimento. Continuando a existir variabilidade, é esperado que antigas respostas selecionadas deixem de existir enquanto outras passem a aparecer com freqüência. A curta manutenção do "supersticioso" parece depender dessa variabilidade no responder: para poucos participantes, o mesmo padrão "supersticioso" foi observado em duas e até em três sessões. Esses resultados replicam, ao longo de mais de uma sessão, o que Ono (1987) chamou de "superstições transitórias". No estudo de Ono, superstições transitórias foram observadas durante a realização de uma única sessão; na presente investigação, foram observadas ao longo de mais de uma sessão.

Diferente do que foi observado por Higgins e cols. (1989), o comportamento "supersticioso" não parece ter sido facilitado pelas instruções que sugeriam a relação de dependência entre resposta e apresentação de pontos. Comportamento "supersticioso" foi produzido no desempenho de P1, P7, P8, P9, P12 e P14 tanto diante de instruções mínimas quanto diante de instruções que sugeriam que os pontos dependiam de respostas (o que pode ser concluído comparando-se o resultado do Experimento 1 com os Experimentos 2 e 3 ); foi produzido para alguns participantes tanto com instruções incoerentes genéricas como com instruções incoerentes mais explícitas (Experimentos 2 e 3).

Os resultados mostram também que o comportamento "supersticioso" foi facilitado por uma alteração nas contingências não-verbais, a introdução do intervalo entre mudança de componentes, mais do que por qualquer manipulação no tipo de instrução (Experimento 2).

Eventualmente, a mera menção, nas instruções, da possibilidade de responder pode ter funcionado como uma instrução suficientemente poderosa para gerar o responder, mas uma conclusão mais parcimoniosa, embora ainda aberta a ser testada por novas investigações, é que o comportamento "supersticioso" produzido em esquemas múltiplos dependeu mais das contingências não-verbais do que propriamente das instruções oferecidas. O uso dos "palpites" pode oferecer possibilidades interessantes para essa análise, pois o palpite testa o controle verbal da descrição sobre o participante: com o participante dizendo o que irá fazer, o palpite testa como a instrução foi "entendida" e até mesmo se ela foi lida. A coleta dos palpites ainda precisa ser aprimorada para que os resultados possam ser mais facilmente analisados.

Explorar a generalidade da interação entre descrição de contingências e efeitos de seleção acidental do responder pode ser um caminho adicional para a avaliação do que costuma ser chamado na análise do comportamento de "insensibilidade" no desempenho de humanos em esquemas de reforço (ver, por exemplo, Cerutti, 1991). A insensibilidade pode não depender apenas de instruções, mas também de quanto o comportamento instruído é mantido ou não por relação acidental com reforço. Essa é, evidentemente, uma questão ainda aberta a muitas outras investigações.

Funcionando como antecedentes verbais para o próprio comportamento, auto-relatos também pareceram ter tido um fraco efeito sobre o desempenho: poucas vezes o participante fazia aquilo que havia descrito na sessão anterior. Assim, instruções, auto- 
relatos ou "palpites" parecem ter tido um papel mínimo na aquisição e manutenção do comportamento "supersticioso" (quando esse responder foi observado). Auto-relatos, em especial, parecem ser mais descrições do próprio comportamento do que parte das contingências que controlam o responder, ou seja, auto-relatos parecem ter sido mais efeitos do que causas na determinação do responder "supersticioso".

$\mathrm{O}$ fato dos auto-relatos poderem ser analisados como descrições do próprio comportamento "supersticioso" sugere um uso mais cuidadoso de expressões como "regras falsas", "regras supersticiosas", "crenças supersticioso" ou "regras inacuradas", porque os participantes podem estar apenas emitindo comportamento verbal sob controle de seus próprios comportamentos. Nesse caso, seriam descrições "verdadeiras" e "acuradas". Skinner (1957) sugeriu a expressão "tato" para designar o operante verbal sob controle discriminativo do ambiente ou de aspectos do ambiente. A expressão auto-tato poderia ser utilizada quando o estímulo discriminativo fosse um aspecto do próprio comportamento ou do corpo do falante. No presente estudo, os participantes estariam, assim, emitindo auto-tatos. Ao descreverem seus próprios comportamentos, a auto-descrição, pode parecer uma regra "falsa" ou "supersticiosa", ou mesmo "incorreta" ou "inacurada", mas só porque o ouvinte não conhece o comportamento "supersticioso" que serviu como antecedente para o auto-relato.

Conceitos tais como ilusões, ilusões de controle e distorções cognitivas sugerem que pensamentos, autodescrições e regras controlam comportamento. Se as descrições são "falsas" ou "supersticiosas", haveria um controle de comportamento disfuncional e problemático para a pessoa. Os resultados do presente estudo sugerem um ponto de vista diferente: contingências e contigüidade entre respostas e mudanças ambientais foram responsáveis tanto pelo comportamento verbal como pelo não-verbal. O que poderíamos chamar de noção de causalidade em uma tarefa relativamente simples foi construída a partir da interação direta dos participantes com as contingências em vigor.

\section{REFERÊNCIAS}

Aeschleman, S. R., Rosen, C. C., \& Williams, R. R. (2003). The effect of non-contingent negative and positive reinforcement operations on the acquisition of superstitious behavior. Behavioural Processes, 61, 37-45.

Assis, F. R. P. (1995). Interação regra contingência: efeitos da história passada no seguimento de instruções sob diferentes es- quemas de reforçamento. Tese de doutorado não-publicada, Universidade de São Paulo.

Beck, A.T., \& Freeman, A. (1993). Terapia cognitiva dos transtornos de personalidade. Porto Alegre: Artes Médicas.

Bloom, C. M., Venard, J., Harden, M., \& Seetharaman, S. (2007). Non-contingent positive and negative reinforcement schedules of superstitious behavior. Behavioural Processes, 75, 8-13.

Catania, A. C. (2003). Verbal governance, verbal shaping, and attention to verbal stimuli. Em K. A. Lattal \& P. N. Chase (Orgs.), Behavior theory and philosophy (pp. 301-321). New York: Kluwer/Academic Press.

Cerutti, D. T. (1991). Discriminative versus reinforcing properties of schedules as determinants of schedule insensitivity in humans. The Psychological Record, 41, 51-67.

Costa, C. E., \& Banaco, R.A. (2002). ProgRef v3: Sistema computadorizado para a coleta de dados sobre programas de reforço com humanos - Recursos básicos. Revista Brasileira de Terapia Comportamental e Cognitiva, 4, 171-172.

Eldridge, G. D., Pear, J. L., Torgrud, L. J., \& Evers, B. H. (1988). Effects of prior response-contingent reinforcement on superstitious behavior. Animal Learning and Behavior, 16, 277-284.

Heltzer, R. A., \& Vyse, S. A.(1994). Intermittent consequences and problem solving: The experimental control of "superstitious" beliefs. The Psychological Record, 44, 155-169.

Herrnstein, R. J. (1966). Superstition: A corollary of the principles of operant conditioning. Em W. K. Honig (Org.), Operant behavior: Areas of research and application (pp. 33-51). New York: Appleton-Century-Crofts.

Higgins, S. T., Morris, E. K., \& Johnson, L. M. (1989). Social transmission of superstitious behavior in preschool children. The Psychological Record, 39, 307-323.

Ninness, H. A., \& Ninness, S. K. (1998). Superstitious math performance: Interactions between rules and scheduled contingencies. The Psychological Record, 48, 45-62.

Ninness, H. A., \& Ninness, S. K. (1999). Contingencies of superstition: Self generated rules and responding during secondorder response-independent schedules. The Psychological Record, 49, 221-243.

Ono, K. (1987). Superstitious behavior in humans. Journal of the Experimental Analysis of Behavior, 47, 261-271.

Ono, K. (1994). Verbal control of superstitious behavior: Superstitions as false rules. Em S. C. Hayes, L. J. Hayes, M. Sato \& K. Ono (Orgs.), Behavior Analysis of Language and Cognition (pp. 181-196). Reno, NV: Context Press.

Pear, J. J. (1985). Spatiotemporal patterns of behavior produced by variable-interval schedules of reinforcement. Journal of the Experimental Analysis of Behavior, 44, 217-231.

Risley, T. R., \& Hart, B. (1968). Developing correspondence between nonverbal and verbal behavior of preschool children. Journal of Applied Behavior Analysis, 11, 267-281.

Rudski, J. M., Lischner, M. I., \& Albert, L. M. (1999). Superstitious rule generation is affected by probability and type of outcome. The Psychological Record, 49, 245-260.

Shimoff, E., \& Catania, A. C. (1998). The verbal governance of behavior. Em K. A. Lattal \& M. Perone (Orgs.) Handbook of research methods in human operant behavior (pp. 371-404). New York: Plenum. 
Skinner, B. F. (1972). Superstition in the pigeon. Em B. F. Skinner, Cumulative record ( $3^{\mathrm{a}}$ ed.) (pp. 524-528). New York: Appleton-Century-Crofts. (Original publicado em 1948)

Skinner, B. F. (1974). About behaviorism. New York: Knopf.

Skinner, B. F. (1957). Verbal behavior. New York: AppletonCentury-Crofts.
Weisberg , P., \& Kennedy, D. B. (1969). Maintenance of children's behavior by accidental schedules of reinforcement. Journal of the Experimental Child Psychology, 8, 222-233.
Recebido: $23 / 08 / 2007$

Última revisão: $22 / 05 / 2008$

Aceite final: 24/05/2008

\section{Notas:}

${ }^{1} \mathrm{O}$ trabalho contou com financiamento na forma de bolsa de Iniciação Científica CEPE PUC para Paulo Panetta e Cássia da Hora e de bolsa de Iniciação Científica CNPq para Silvia Ferrari. Todos os trabalhos foram orientados pelo primeiro autor.

${ }^{2}$ As instruções do Experimento 1 começavam com a frase "Você participará de algumas sessões experimentais". Essa frase foi retirada nos Experimentos 2 e 3 .

\section{Sobre os autores:}

Marcelo Benvenuti: Doutor em Psicologia Experimental pela USP. Professor da Faculdade de Psicologia da PUC-SP. Atualmente, Professor Convidado no Programa de Pós-graduação em Ciências do Comportamento da UnB.

Paulo Panetta: Graduado em Psicologia e Mestre em Psicologia Experimental pela PUC-SP.

Cássia da Hora: Graduada em Psicologia pela PUC-SP, atualmente mestranda em Psicologia Experimental na USP.

Silvia Ferrari: Graduada em Psicologia pela PUC-SP.

Endereço para correspondência: mbenvenuti@yahoo.com 